\title{
Severe clinical conditions associated with Bacillus cereus and the apparent involvement of exotoxins
}

\author{
P. C. B. TURNBULL, KIRSTEN JøRGENSEN, J. M. KRAMER, R. J. GILBERT, \\ AND JENNIFER M. PARRY \\ From the Food Hygiene Laboratory, Central Public Health Laboratory, Colindale Avenue, London NW9 \\ $5 H T$, and the Institute of Hygiene and Microbiology, Royal Veterinary and Agricultural University, \\ Copenhagen $V$, Denmark
}

SUMMARY Twenty-one cases of infection with Bacillus cereus are summarised. The histories supplied showed that at least 15 of these were associated with severe or potentially severe symptoms including two deaths. Analysis of the production of exotoxins, including haemolysin and phospholipase, by these strains is given, and the relevance of these metabolites to the severity of the condition is discussed. Three incidents of bovine mastitis resulting from $B$. cereus and involving three deaths are also included.

The observations presented here together with those of previous reports which are reviewed indicate that $B$. cereus may be of clinical importance, not just as an opportunist but also as an agent of potentially severe infections in its own right.

The predominant interest in Bacillus cereus over the past decade has been from the standpoint of its role in food poisoning. However, the association of this organism with clinical conditions not related to food and often severe in nature has been pointed out from time to time for many years. Despite this, hospital microbiologists often readily admit that they frequently see the organism but almost invariably dismiss it as unimportant.

Contributing to the lack of appreciation of the potential pathogenicity of $B$. cereus was the uncertain taxonomy of the species before the 1950s. Although the specific name $B$. cereus was applied to a pathogenic blood culture isolate as early as 1937 (Clarke), up to about 1950 the organism, as far as can be established (Gibson and Gordon, 1974). was sometimes grouped with various other species under B. subtilis (Weinstein and Colburn, 1950), sometimes under $B$. anthracoides (or just 'anthracoids') of which it was probably the predominant member, and sometimes under what were probably more specific names, $B$. subtilis mycoides, $B$. siamensis, B. anthracis similis, and B. pseudoanthracis.

Under one or other of these names, or even less specifically, simply 'aerobic spore bearer' (ASB), it is likely that $B$. cereus was the organism associated with numerous clinical manifestations. In papers

Received for publication 11 September 1978 on this subject, Heaslip (1941), Weinstein and Colburn (1950), Farrar (1963), and Goepfert et $a^{\prime}$. (1972) cite some 20 reports between 1898 and 1937 in which organisms under these names were associated with abscess formation, severe eye infections, meningitis, kidney and urinary tract infections, puerperal sepsis, pulmonary infections, septicaemias, and war wounds. ASBs also featured in war wounds of the second world war (Spooner, 1941), and clinicians today who were practising at that time testify to the severity of war wounds infected with anthracoids.

Classification of the species under the name B. cereus was fully established in 1952 (Smith et al.), and under this name the organism has continued to be recorded as the cause of bacteraemia and septicaemia (Curtis et al., 1967; Crowley, 1970; Leffert et al., 1970; Coonrod et al., 1971; Goullet and Pépin, 1974; Raphael and Donaghue, 1976; Barnham and Taylor, 1977; Chastel et al., 1977), pneumonia and pleurisy (Stopler et al., 1964; LeLourd et al., 1967; Coonrod et al., 1971 ; Feldman and Pearson, 1974; Leff et al., 1977), endocarditis (Craig et al., 1974; Block et al., 1978), gas gangrenelike infections (Gröschel et al., 1976; Turnbull et al., 1977a), meningitis (Leffert et al., 1970; Raphael and Donaghue, 1976), cerebral necrosis (Turnbull et al., 1977a), middle-ear infection (Lázár and Jurecsák, 1966), osteomyelitis (Solny et al., 1977), and urinary 
tract infection (Melles et al., 1969).

References to severe $B$. cereus infections in domestic animals are also readily obtainable, especially with respect to gangrenous mastitis in cattle (Jasper et al., 1972; Wohlgemuth et al., 1972).

As a result of the role of this organism in food poisoning, the Food Hygiene Laboratory has become a centre of reference for $B$. cereus and in the past two years has begun to receive increasing numbers of isolates from clinical cases not related to food. With a concurrent development of our knowledge of exotoxin production within the species, an interesting picture is emerging in which the extent of production of specific toxin activities by an isolate appears to be related to the severity of the condition.

\section{Methods}

ISOLATES EXAMINED

The strains and their isolation histories are sum- marised in Table 1. Five of these derived from countries outside the British Isles. All were routinely confirmed biochemically as $B$. cereus, and their serotypes were determined (Taylor and Gilbert, 1975). A number of these strains have featured in previous publications, as indicated in Table 1.

\section{TOXIN TESTS}

Nine-hour cultures of the organisms in Brain-Heart Infusion Broth (Difco) containing 0.1\% glucose (BHIG) shaken at approximately 100 cycles/min at $36^{\circ} \mathrm{C}$ were centrifuged and filtered.

For vascular permeability reaction, including skin necrosis tests (VPR), $0.05 \mathrm{ml}$ of cell-free filtrates was inoculated intradermally in duplicate into the shaved backs of two adult rabbits. At 3 hours postinoculation approximately $4 \mathrm{ml}$ of $2 \%$ Evans Blue dye was injected intravenously, and measurements of blueing and necrosis were made after a further hour.

For rabbit intestinal necrosis reactions the cell-free filtrates were concentrated four-to seven-fold and

Table 1 Association of Bacillus cereus and its exotoxins* with severe infection

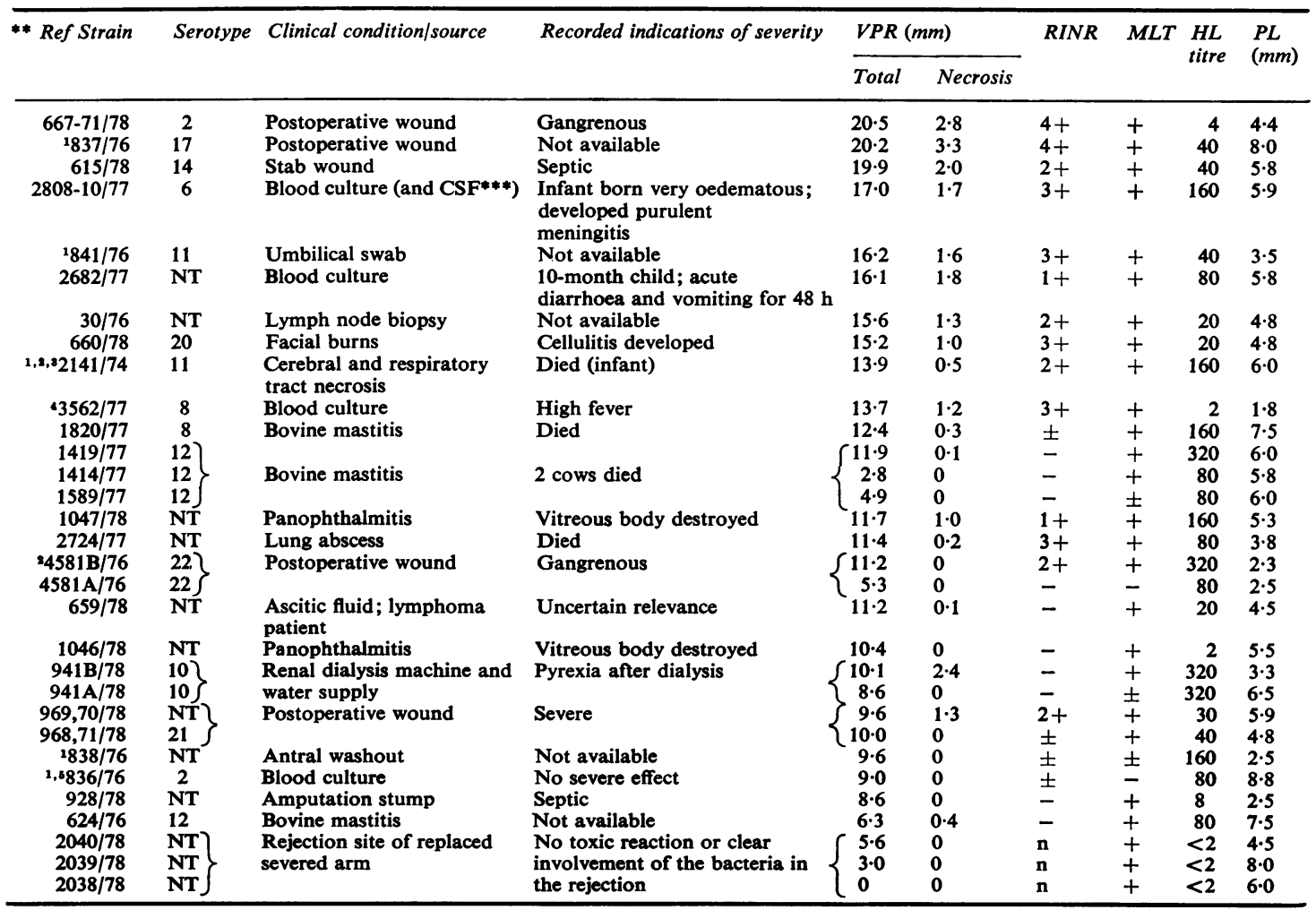

VPR = vascular permeability reaction; $R I N R=$ rabbit intestinal necrosis reaction; $M L T=$ mouse lethal test; $H L=$ haemolysin; PL $=$ phospholipase. **1 Turnbull et al. (1977b); ' Turnbull et al. (1977a); ' Turnbull (1976); Chaslel et al. (1977); ' Barnham and Taylor (1977). **Culture was not available. $\mathrm{NT}=$ not typable. $\mathrm{n}=$ not done. 
injected into ligated rabbit intestines, and the results were recorded as previously described (Turnbull et al., 1977b).

For mouse lethal tests, $0.5 \mathrm{ml}$ of the unconcentrated cell-free filtrates was injected into the tail veins of duplicate adult mice and the mice were observed for 45 minutes.

Haemolysin titrations were carried out according to the method of Johnson and Bonventre (1967) using two-fold serial dilutions of culture supernatants incubated with $0.5 \%$ rabbit erythrocytes in $0.85 \%$ saline.

Phospholipase activities were determined as the mean radii of zones of opacity forming after 20 hours at $36^{\circ} \mathrm{C}$ around duplicate $5 \mathrm{~mm}$ wells in an egg-yolk-mannitol based agar containing $50 \mu \mathrm{l}$ of the cell-free filtrate.

\section{Results and Discussion}

The toxin profiles of the isolates are given in Table 1 . The strains are listed in order of decreasing VPR, which is an established measure of exotoxins of microorganisms which increase the permeability of cutaneous blood vessels to plasma proteins at the site of injection (Craig, 1971). In the case of $B$. cereus, high levels of production of this toxin result additionally in development of necrosis within a few minutes. The total reaction is the sum of the mean radii (in millimetres) of the zones of light and dark blueing and, when present, necrosis. Although given to the first decimal place for the convenience of placing the strains in order, the values should not be interpreted too precisely and can vary by two or three units on repeated testing; this reflects not only animal to animal differences but also some variations in other factors such as growth of the organisms from batch to batch of BHIG.

In a study on production of this toxin by 116 strains of $B$. cereus from a wide variety of sources (Turnbull et al., 1979), it was found that the strains could be conveniently placed, on the basis of total VPR, into five categories: (1) $0-4 \cdot 9$; (2) $5 \cdot 0-9.9$; (3) $10 \cdot 0-14.9$; (4) $15 \cdot 0-19 \cdot 9$; (5) $20 \cdot 0-24 \cdot 9$. For the purposes of general interpretation, categories 4 and 5 represent strong production of the toxin, 2 and 3 intermediate production, and 1 weak production. Since only about $7.5 \%$ of $B$. cereus strains so far tested fall into category 1 , it is presumed that the majority of strains are potentially capable of causing severe effects under the appropriate circumstances of infection.

In 19 of the 24 cases listed in Table $1, B$. cereus strains of categories 3,4 , and 5 were isolated. On five occasions more than one strain of $B$. cereus was isolated from a single case; in four of these, one of the variants showed an apparently greater ability to produce this toxin than the others and was presumed to be of predominant importance in the infection. In the fifth case (strains 2038-40/78), the low toxigenicity of all isolates from the rejection site correlated well with the clinical opinions expressed that, on the basis of an absence of gross necrosis, gas formation or foci of Gram-positive organisms in the rejected portion of the arm, and the absence of a toxic reaction in the patient, $B$. cereus was not responsible for the rejection. Strain $841 / 76$ was found to elaborate this toxin more strongly than had previously been observed (Turnbull et al., 1977b).

If every $\boldsymbol{B}$. cereus isolation in a hospital laboratory was uncritically recorded, it would be difficult to distinguish those causally associated from those incidentally associated with clinical conditions. However, the probability that the implicated strains listed in Table 1 did have active roles in their respective cases is increased by the fact that, at the present time, this organism is generally regarded as having little clinical significance. It is likely, therefore, that, with the exception of strains 2038-40/78, where it was stated otherwise, only strains that drew attention to themselves either in being sole isolates or through their repeated isolation or by their predominance, would have been forwarded to the Food Hygiene Laboratory for further examination. These criteria should continue to be kept in mind in attempts to assess the relevance of $B$. cereus isolations from infections.

In nine of the cases (including the bovine mastitis), it was categorically stated that $B$. cereus was isolated in pure culture, and this was implied in a further two cases. In two more cases it was the only organism consistently isolated on several occasions, and in another two cases it was recorded as the only organism of possible significance. Other organisms of possible significance were reported in five cases, and the information was not available in the remaining four.

Correlation between VPR readings and the degree of necrotic damage qualitatively assessed in the rabbit intestinal necrosis model is good at the high and low levels of toxin production; there is some variance at intermediate levels, but this is as anticipated in animal tests for which there are limits to the extent of repetition that is feasible.

Mouse lethality is the longest standing pathogenicity test used for $B$. cereus. The role in severe human infections of the toxins that kill mice is also conjectural. Using fractions of BHIG culture filtrates partially purified by flat-bed electrofocusing, Turnbull et al. (1979) have obtained evidence that there are two lethal factors, one closely associated 
Table 2 Antibiotic sensitivity patterns in the 39 Bacillus cereus isolates of Table 1

\begin{tabular}{|c|c|c|c|c|c|c|c|c|c|c|c|c|c|c|c|}
\hline \multirow{2}{*}{$\begin{array}{l}\text { No. strvins } \\
\text { tested }\end{array}$} & \multicolumn{3}{|c|}{$5 \mu \mathrm{g}$ erythromycin } & \multicolumn{3}{|c|}{1 unit penicillin $G$} & \multicolumn{3}{|c|}{$10 \mu \mathrm{g}$ tetracycline } & \multicolumn{3}{|c|}{$10 \mu \mathrm{g}$ gentamicin } & \multicolumn{3}{|c|}{$25 \mu \mathrm{g}$ cephaloridine } \\
\hline & $S$ & $I$ & $\boldsymbol{R}$ & $S$ & $I$ & $\boldsymbol{R}$ & $S$ & $I$ & $\boldsymbol{R}$ & $S$ & $\boldsymbol{I}$ & $\boldsymbol{R}$ & $S$ & $I$ & $\boldsymbol{R}$ \\
\hline 39 & 36 & 3 & 0 & $* 1$ & 3 & 35 & 33 & 4 & 2 & 39 & 0 & 0 & $* 1$ & 38 & 0 \\
\hline
\end{tabular}

$S=$ sensitive, $I=$ intermediate $; R=$ resistant $; * 3562 / 77$

with the rabbit intestinal necrosis reaction and its associated VPR factors and a second which is quite distinct and is associated with a haemolysin.

The haemolysin and phospholipase activities have also been viewed in the past as having a possible role in the pathogenic action of $B$. cereus. Wide variations in general haemolytic or phospholipolytic activities were obtained among the strains tested; in the case of haemolysins, there is clearly no relationship between titre and pathogenicity. The nature and interrelationships of the haemolysin, phospholipase, and lethal activity are reviewed elsewhere (Johnson and Bonventre, 1967; Bonventre and Johnson, 1970; Spira and Goepfert, 1975).

Pathogenicity studies on $B$. cereus and related organisms are numerous; the earlier ones were primarily concerned with differentiating $B$. anthracis from $B$. cereus. Studies relevant to this report are covered by other authors (Grierson, 1928; Burdon et al., 1967; Stamatin and Anghelesco, 1969; Stretton and Bulman, 1975).

The distribution of serotypes is of interest in that, of those represented in these cases, only types 8 and 17 are at all commonly encountered in the Food Hygiene Laboratory.

Both the references reviewed and the findings presented here suggest that $B$. cereus may cause serious infections other than those of a gastrointestinal nature and that such infections are possibly occurring throughout the world more frequently than is appreciated. In many of the cases listed, the patients were reported to have responded favourably to the appropriate antibiotic therapy, but it is also seen that 'ethalities can occur in both man and animals. Table 2 gives the antibiotic patterns in a disc diffusion sensitivity test using the Oxford strain of Staphylococcus aureus (NCTC 6571) as the control and the Stokes (1968) method of interpretation.

The toxin responsible for the purulent and necrotic nature of many $B$. cereus infections appears to be closely related or identical with the toxin responsible for the diarrhoeal-type syndrome associated with this organism, and some characterisation of this toxin has been achieved (Turnbull et al., 1979).

We are grateful to the microbiologists and clinicians who supplied us with the cultures and case histories that made this paper possible.

\section{References}

Barnham, M., and Taylor, A. J. (1977). A case of Bacillus cereus bacteraemia. Postgraduate Medical Journal, 53, 397-399.

Block, C. S., Levy, M. L., and Fritz, V. U. (1978). Bacillus cereus endocarditis. A case report. South African Medical Journal, 53, 556-557.

Bonventre, P. F., and Johnson, C. E. (1970). Bacillus cereus toxin. In Microbial Toxins, 3, Bacterial Protein Toxins, edited by T. C. Montie, S. Kadis., and S. J. Ajl, pp. 415-435. Academic Press, London and New York.

Burdon, K. L., Davis, J. S., and Wende, R. D. (1967). Experimental infection of mice with Bacillus cereus: studies of pathogenesis and pathologic changes. Journal of Infectious Diseases, 117, 307-316.

Chastel, C., Goas, J. Y., Masure, O., and Bastard, J. (1977). Un nouveau cas de bactériémie à Bacillus cereus (Letter). Nouvelle Presse Médicale, 6, 1659.

Clark, F. E. (1937). The relation of Bacillus siamensis and similar pathogenir: srore-forming bacteria to Bacillus ceieus. Journal o Ructeriology, 33, 435-443.

Coonrod, J. D., Leadley, P. J., and Eickhoff, T. C. (1971). Bacillus cereus pneumonia and bacteremia. American Review of Respiratory Disease, 103, 711-714.

Craig, J. P. (1971). Cholera toxins. In Microbial Toxins, $2 A$, Bacterial Protein Toxins, edited by S. Kadis, T. C. Montie, and S. J. Ajl, pp. 189-254. Academic Press, London and New York.

Craig, C. P., Lee, W. S., and Ho, M. (1974). Bacillus cereus endocarditis in an addict (Letter). Annals of Internal Medicine, 80, 418-419.

Crowley, N. (1970). Some bacteraemias encountered in hospital practice. Journal of Clinical Pathology, 23, 166-171.

Curtis, J. R. Wing, A. J., and Coleman, J. C. (1967). Bacillus cereus bacteraemia. A complication of intermittent haemodialysis. Lancet, 1, 136-138.

Farrar, W. E., Jr. (1963). Serious infections due to "non-pathogenic" organisms of the genus Bacillus. American Journal of Medicine, 34, 134-141.

Feldman, S., and Pearson, T. A. (1974). Fatal Bacillus cereus pneumonia and sepsis in a child with cancer. Clinical Pediatrics, 13, 649-655.

Gibson, T., and Gordon, R. E. (1974). Genus Bacillus, 4. Bacillus cereus. In Bergey's Manual of Determinative 
Bacteriology, edited by R. E. Buchanan, and N. E. Gibbons, 8th edition, pp. 534-535. Williams and Wilkins, Baltimore.

Goepfert, J. M., Spira, W. M., and Kim, H. U. (1972). Bacillus cereus: food poisoning organism. A review. Journal of Milk and Food Technology, 35, 213-227.

Goullet, P., and Pépin, H. (1974). Une septicémie à Bacillus cereus. Nouvelle Presse Médicale, 3, 2490-2492.

Grierson, A. M. M. (1928). "Bacillus anthracoides". A study of its biological characters and relationships and its pathogenic properties under experimental conditions. Journal of Hygiene, 27, 306-320.

Gröschel, D., Burgess, M. A., and Bodey, G. P. (1976). Gas gangrene-like infection with Bacillus cereus in a lymphoma patient. Cancer, 37, 988-991.

Heaslip, W. G. (1941). Bacillus tropicus, a new species isolated from man and animals described and compared with other bacilli resembling Bacillus anthracis. Medical Journal of Australia, 2, 536-540.

Jasper, D. E., Bushnell, R. B., Dellinger, J. D., and Stang, A. M. (1972). Bovine mastitis due to Bacillus cereus. Journal of the American Veterinary Medical Association, 160, 750-756.

Johnson, C. E., and Bonventre, P. F. (1967). Lethal toxin of Bacillus cereus. I. Relationships and nature of toxin, hemolysin and phospholipase. Journal of Bacteriology, 94, 306-316.

Lázár, J., and Jurecsák, L. (1966). Daten zur Pathogenität des B. cereus. Zentralblatt für Bakteriologie, Parasitenkunde, Infektionskrankheiten und Hygiene. I. Abteilung: Originale, 199, 59-64.

Leff, A., Jacobs, R., Gooding, V., Hauch, J., Conte, J., and Stulbarg, M. (1977). Bacillus cereus pneumonia. Survival in a patient with cavitary disease treated with gentamicin. American Review of Respiratory Disease, 115, 151-154.

Leffert, H. L., Baptist, J. N., and Gidez, L. I. (1970). Meningitis and bacteremia after ventriculoatrial shunt-revision: isolation of a lecithinase-producing Bacillus cereus. Journal of Infectious Diseases, 122, 547-552.

LeLourd, R., Domec, L., and LeLourd, F. (1967). Pleurésie purulente à Bacillus cereus chez une asthmatique traitée au long cours par les corticoides. Semaine des Hôpitaux de Paris, 43, 2730-2731.

Melles, Z., Nikodémusz, I., and Ábel, A. (1969). Die pathogene Wirkung aerober sporenbildender Bakterien. Zentralblatt für Bakteriologie, Parasitenkunde, Infektionskrankheiten und Hygiene. I. Abteilung: Originale, 212, 174-176.

Raphael, S. S., and Donaghue, M. (1976). Infection due to Bacillus cereus (Letter). Canadian Medical Association Journal, 115, 207.

Smith, N. R., Gordon, R. E., and Clark, F. E. (1952). Aerobic Sporeforming Bacteria (United States Department of Agriculture, Monographs, No. 16), pp. 56-64. Washington, D. C.
Solny, M. N., Failing, G. R., and Borges, J. S. (1977). Bacillus cereus osteomyelitis (Letter). Archives of Internal Medicine, 137, 401-402.

Spira, W. M., and Goepfert, J. M. (1975). Biological characteristics of an enterotoxin produced by Bacillus cereus. Canadian Journal of Microbiology, 21, 1236-1246.

Spooner, E. T. C. (1941). The bacteriology of air-raid wounds examined within forty-eight hours of infliction. British Medical Journal, 2, 477-478.

Stamatin, N., and Anghelesco, S. (1969). Pouvoir pathogène et toxicité de Bacillus cereus. Annales de l'Institut Pasteur, 116, 210-217.

Stokes, E. J. (1968). Clinical Bacteriology, 3rd edition, p. 179. Edward Arnold, London.

Stopler, T., Cámuescu, V., and Voiculescu, M. (1964). Bronchopneumonia with fatal evolution caused by a microorganism of the Bacillus species (B. cereus). (Rumanian). Microbiologia, Parazitologia, Epidemiologia, 9, 457-460.

Stretton, R. J., and Bulman, R. A. (1975). Experimental infection of rabbits with Bacillus cereus. Zentralblatt für Bakteriologie, Parasitenkunde, Infektionskrankheiten und Hygiene. I. Abteilung: Originale, A, 232, 83-90.

Taylor, A. J., and Gilbert, R. J. (1975). Bacillus cereus food poisoning: a provisional serotyping scheme. Journal of Medical Microbiology, 8, 543-550.

Turnbull, P. C. B. (1976). Studies on the production of enterotoxins by Bacillus cereus. Journal of Clinical Pathology, 29, 941-948.

Turnbull, P. C. B., French, T. A., and Dowsett, E. G. (1977a). Severe systemic and pyogenic infections with Bacillus cereus. British Medical Journal, 1, 1628-1629.

Turnbull, P. C. B., Kramer, J. M., Jørgensen, K., Gilbert, R. J., and Melling, J. (1979). Properties and production characteristics of vomiting, diarrheal, and necrotizing toxins of Bacillus cereus. American Journal of Clinical Nutrition, 32, 219-228.

Turnbull, P. C. B., Nottingham, J. F., and Ghosh, A. C. (1977b). A severe necrotic enterotoxin produced by certain food, food poisoning and other clinical isolates of Bacillus cereus. British Journal of Experimental Pathology, 58, 273-280.

Weinstein, L., and Colburn, C. G. (1950). Bacillus subtilis meningitis and bacteremia : report of a case and review of the literature on "subtilis" infections in man. Archives of Internal Medicine, 86, 585-594.

Wohlgemuth, K. Kirkbride, C. A., Bicknell, E. J., and Ellis, R. P. (1972). Pathogenicity of Bacillus cereus for pregnant ewes and heifers. Journal of the American Veterinary Medical Association, 161, 1691-1695.

Requests for reprints to: Dr Peter C. B. Turnbull, Food Hygiene Laboratory, Central Public Health Laboratory, Colindale Avenue, London NW9 5HT. 